\title{
Effect of hot isostatic pressing on densification, microstructure and nanoindentation behaviour of Mg-SiC nanocomposites
}

\author{
Daniela Hübler $^{1, \star}$ (D), Alireza Ghasemi ${ }^{1}$, Ralf Riedel ${ }^{2}$, Claudia Fleck $^{1, \star}$, and Sepideh Kamrani ${ }^{1}$ \\ ${ }^{1}$ Faculty III-Process Sciences, Institute of Material Science and Technology, Chair of Materials Science and Engineering, Technische \\ Universität Berlin, Straße des 17. Juni 135, 10623 Berlin, Germany \\ ${ }^{2}$ Department of Materials and Earth Sciences, Group Dispersive Solids, Technische Universität Darmstadt, Otto-Berndt-Straße 3, \\ 64287 Darmstadt, Germany
}

Received: 7 January 2020

Accepted: 29 April 2020

Published online:

13 May 2020

(C) The Author(s) 2020

\begin{abstract}
The production of fully dense nanocomposites with a homogeneous distribution of nanoparticles through powder metallurgy (PM) techniques is challenging. Additionally to mechanical milling, pressing and sintering, a final consolidation process is needed to fully densify the nanocomposite. Hot isostatic pressing (HIP) is a promising alternative method to other hot forming processes to eliminate porosity in these PM parts. In contrast to hot extrusion, for instance, isotropic properties are achieved, and textures, as they are usually observed in $\mathrm{Mg}$ after uniaxial deformation, are avoided. Here, we evaluate the effect of HIP on the densification, microstructure and (nano)hardness of $\mathrm{Mg}-\mathrm{SiC}$ nanocomposites. Even though density increased indeed, we observed no increase in the mechanical properties, due to significant heterogeneity in the microstructure. SiC-free regions with a higher grain size developed. Local nanohardness measurements of the HIPed $\mathrm{Mg}$ nanocomposite revealed that these regions had a significantly lower nanohardness than the SiC-containing regions. Under consideration of mechanisms reported to be active in $\mathrm{Mg}$ in the pressure and temperature regime we used, we conclude that grain growth is the most likely mechanism leading to the microstructure observed after HIP. This is driven by the thermodynamic pressure to decrease the grain boundary energy and facilitated by a slightly inhomogeneous distribution of $\mathrm{SiC}$ nanoparticles in the sintered nanocomposite.
\end{abstract}

Claudia Fleck and Sepideh Kamrani contributed equally to the paper.

Address correspondence to E-mail: huebler@tu-berlin.de; claudia.fleck@tu-berlin.de 


\section{Introduction}

Strength and stiffness of metallic materials can be significantly improved compared to the pure metal by adding nanoscale particles, thus designing metalmatrix nanocomposites (MMNC) [1-3]. Such nanocomposites are usually processed through a powder metallurgical (PM) route, comprising mechanical powder compaction and sintering steps. However, achieving full density while keeping the ultrafine microstructure during the consolidation process is still a challenge. This is why an additional consolidation process is needed to fully densify the material. HIP is a promising method to eliminate porosity in these PM parts. Thus, components can be designed, which meet the specifications for use in highly stressed applications [4]. In comparison with hot extrusion as additional consolidation step, HIP avoids texture formation and, therefore, anisotropic properties due to the uniformly applied pressure. The pressure can additionally help to overcome restraining effects in composites due to nanoparticles compared to sintering [5]. Further advantages of the HIP process in general are the production of near-net shaped structures and the greater design freedom in comparison with hot extrusion [6].

Powder is often directly HIPed in a vacuum-sealed flexible capsule. However, the capsule has to be removed after HIP by machining, pickling or sandblasting [7]. Another alternative is the sinter-HIP process which combines two steps and consolidates precompacted powder, while preventing oxidation due to a better control of atmosphere and reducing the risk of grain growth due to the eliminated reheating in the second step [5,7]. However, in our case, we separated the process in two steps sintering and HIP in order to characterise the mechanisms occurring during the individual process steps.

While for pure metal powders plastic deformation and creep are possible dominant mechanisms for improving the compaction during HIP [8], creep plays, however, only a minor role in the compaction of metal composite powders due to the nanoparticles [9].

Thus, hipping composites seems to involve different mechanisms than hipping pure metals. Until now, only a few studies on HIP of metal-matrix composites exist. But HIP has a high potential of achieving full theoretical density and of reaching a uniform compaction, while reducing the overall property scatter, as $\mathrm{Xu}$ et al. showed for a cast $\mathrm{Al}-\mathrm{SiC}$ composite [10]. They further showed that yield stress decreased drastically as ductility increased mainly due to the reduction of porosity. Lange et al. investigated the influence of microinclusions on densification during HIP: inclusion volume fractions above $20 \%$ lead to inclusion networks which substantially reduced the densification rate [9]. Thus, even though the reinforcing phase constrains the deformation, strength and creep resistance of the products are nevertheless increased compared to the pure metal. For nanocomposites, this means that the amount of reinforcement has to be as small as possible, while still retaining the positive effects of nanoparticles such as Orowan strengthening and hindering of grain growth.

To the best of our knowledge, there are no reports regarding HIP of magnesium nanocomposites. We investigated the effect of HIP on the densification, the microstructure and the mechanical properties of a $\mathrm{Mg}-\mathrm{SiC}$ nanocomposite with a reinforcement content of $1 \mathrm{vol} \% \mathrm{SiC}$ nanoparticles compared to non-reinforced Mg. Besides microhardness, we discuss our findings regarding nanohardness and effective elastic modulus of non-reinforced $\mathrm{Mg}$ and $\mathrm{Mg}-\mathrm{SiC}$ nanocomposite locally at the micron to the submicron scale. We then compare our findings on the densification during HIP and the resulting mechanical properties with those achieved by extrusion of $\mathrm{Mg}-$ $\mathrm{SiC}$ nanocomposites which we reported previously [11].

\section{Experimental procedure}

\section{Processing}

Nanocomposite powders with a reinforcement content of 1 vol \% SiC nanoparticles were prepared by high-energy mechanical milling, precompacted by uniaxial pressing and further compacted by coldisostatic pressing (CIP) before sintering (see Table 1). Further details are given in our previous works $[11,12]$. To achieve fully dense bodies and isotropic properties, HIP was applied as additional consolidation step. The surface of the sintered samples was first ground to remove the oxide layer. Then, HIP was performed under argon atmosphere. The HIP unit was preheated to $200{ }^{\circ} \mathrm{C}$ for $1 \mathrm{~h}$ followed by pressure 
Table 1 Overview of the process parameters

\begin{tabular}{lllll}
\hline & Temperature $\left({ }^{\circ} \mathrm{C}\right)$ & Time $(\mathrm{h})$ & Pressure $(\mathrm{MPa})$ & Atmosphere \\
\hline Mechanical milling & - & 25 & - & Argon \\
Cold-isostatic pressing & - & $10 \mathrm{~min}$ & 700 & Oil \\
Sintering & 600 & 2 & - & Argon \\
\hline
\end{tabular}

build-up to $100 \mathrm{MPa}$ over $2 \mathrm{~h}$. After a pressure of $100 \mathrm{MPa}$ was reached, the unit was heated up to $500{ }^{\circ} \mathrm{C}$ with a heating rate of $5 \mathrm{~K} \mathrm{~min}^{-1}$. After a holding time of $1 \mathrm{~h}$, the unit was cooled down to room temperature with a cooling rate of $3 \mathrm{~K} \mathrm{~min}^{-1}$ before the pressure was released. As a reference, nonreinforced $\mathrm{Mg}$ samples were produced in the same way as the $\mathrm{Mg}$ nanocomposite. Henceforth, the samples will be referred to as "non-reinforced $\mathrm{Mg}^{\text {", }}$ "Mg" and "Mg nanocomposite", "Mg-SiC".

\section{Microstructural analysis}

The microstructure and the porosity of the samples following sintering and HIP were investigated on ground and polished sections. After grinding with sandpaper up to 4000-grit with ethanol as lubricant, the sections were stepwise polished, using diamond spray down to $1 / 4 \mu \mathrm{m}$ particle size (Struers), cleaned with ethanol and blow-dried. The pore shape and distribution and the characteristics of the nanoindents were investigated by scanning electron microscopy (SEM), using a Gemini SEM 500 (Zeiss, Germany) in secondary electron (SE) mode at an accelerating voltage of $8 \mathrm{kV}$. The grain structure of the $\mathrm{Mg}$ matrix and the reinforcement distribution were evaluated qualitatively by transmission electron microscopy (TEM, Tecnai G 20 S-TWIN, FEI, USA), on a specimen prepared parallel to the uniaxial pressing direction by the focused ion beam (FIB) technique. For quantification of the grain size and to obtain a statistical grain size distribution, the diameters of at least $200 \mathrm{Mg}$ grains were measured in dark field TEM micrographs using the measuring tool of the ImageJ software (National Institute of Health, USA). Further, scanning transmission electron microscopy (STEM) was used to analyse the elemental composition of the $\mathrm{Mg}$ grains and the grain boundaries by an energy-dispersive X-ray spectroscopy (EDS) line scan.

The relative density of the materials was determined by 2D pore analysis on SEM images by ImageJ. At least 5 SEM images of different regions of the cross section of each sample were analysed with the help of the tool "Analyze Particles" at a magnification of 500 after digital enhancement of the contrast and segmentation. The percentage amount of pores was determined within a region of interest sized $113 \mu \mathrm{m} \times 78 \mu \mathrm{m}$ in each of the five micrographs.

\section{Mechanical properties}

The mechanical properties were investigated by micro- and nanoindentation for the sintered and sintered/HIPed states. Sections were prepared and polished as described above for the microstructural analysis. For the microhardness measurements, a Zwick 3212 (Germany) microhardness tester was used with a maximum force of $1.961 \mathrm{~N}$ (HV 0.2) and a dwell time of $10 \mathrm{~s}$. To quantify the local hardness, nanoindentation was performed with a Hysitron TI 950 TriboIndenter (Bruker Corporation, Massachusetts, USA) equipped with a standard Berkovich diamond indenter tip. A maximum load of $1 \mathrm{mN}$ with a dwell time of $10 \mathrm{~s}$ and a loading and unloading rate of $200 \mu \mathrm{N} \mathrm{s}^{-1}$ were used. At least 100 indents were made in several areas of each sample in grid-wise arrangements of $5 \times 5$ indents with a distance of $15 \mu \mathrm{m}$ between the single indents to obtain a statistically significant average of nanohardness $\left(H_{n}\right)$ and effective elastic modulus ( $\left.E_{\text {eff }}\right)$. As Si-free and Sicontaining regions were identified in the HIP $\mathrm{Mg}$ nanocomposites (see below, ch. 3.1, Fig. 2), additionally at least 50 indents were made for local nanohardness measurements in each of the two different regions using grids of $3 \times 1$ indents with a distance between single indents of $10 \mu \mathrm{m}$. Nanohardness and $E_{\text {eff }}$ were determined by the method described by Oliver and Pharr [13, 14]. The statistical significance was determined homoscedastic using a $t$ test and a two-tailed distribution at a significance level of $\alpha=0.05$ [15]. 


\section{Results}

\section{Microstructural characterisation}

Figure 1 shows SEM micrographs of typical metallographic sections of a non-reinforced $\mathrm{Mg}$ and a $\mathrm{Mg}$ nanocomposite specimen both after sintering (Fig. 1 a, b) and after HIP (Fig. 1 c, d). The Mg matrix appears light grey, while the former powder particle boundaries are dark grey and the pores black. The sintered samples have an almost uniform distribution of the pores. $\mathrm{Mg}$ exhibits more equiaxed pores (arrows), while the $\mathrm{Mg}-\mathrm{SiC}$ contains elongated as well as equiaxed pores. The elongated pores appear along the contact points of former powder particles. They are thus arranged along lines, resembling a string of pearls surrounding the grains. These pores seem to be separated by thin struts of material. After HIP, the samples still show pores; in some areas, these are homogeneously distributed, in others, however, they are clustered in string-like lines, just as in the sintered nanocomposite. While the $\mathrm{Mg}$ does not show a significantly different pore shape compared to the sintered state, the $\mathrm{Mg}-\mathrm{SiC}$ exhibits more ellipsoidal and equiaxed pores with micron and submicron sizes. Although both sintered samples exhibit different pore morphologies, the relative densities of the nonreinforced $\mathrm{Mg}$ and the $\mathrm{Mg}$ nanocomposite are similar (Table 2). In contrary, after HIP, the Mg-SiC nanocomposite exhibits the highest density,
Table 2 Relative density of sintered and HIPed samples determined by $2 \mathrm{D}$ pore analysis

\begin{tabular}{lll}
\hline & \multicolumn{2}{l}{ Relative density (\%) } \\
\cline { 2 - 3 } & Sintered & HIP \\
\hline Non-reinforced Mg & 97.9 & 98.1 \\
Mg nanocomposite & 97.5 & 99.1 \\
\hline
\end{tabular}

compared to the sintered state as well as compared to the pure $\mathrm{Mg}$ sample.

A more detailed characterisation of the microstructure of the HIPed $\mathrm{Mg}-\mathrm{SiC}$ is possible by SEM investigations. At a low magnification (Fig. 2a), we observe two different areas: one appearing in dark grey and the other one in light grey. The latter is much more abundant, comprising approximately 70 to $80 \%$ of the area, thus representing the major part of the sample. The maximum extension of the dark grey regions seems to be on the range of $40 \mu \mathrm{m}$. Figure $2 \mathrm{~b}$ shows the microstructure in more detail. The areas appearing in dark grey at the lower magnification show less contrast at this magnification and have been marked with dashed lines for clarity. Figure 2c shows elemental maps of $\mathrm{Si}$ and $\mathrm{Mg}$ in the light and dark grey areas which prove that the dark and light grey areas are regions free of $\mathrm{Si}$ and regions containing $\mathrm{Si}$, respectively. Accordingly, the dark grey areas will be referred to as "SiC-free regions" in the following.
Figure 1 SEM micrographs of $\mathbf{a}, \mathbf{b}$ sintered and $\mathbf{c}, \mathbf{d}$ HIPed non-reinforced $\mathrm{Mg}$ and $\mathrm{Mg}$ nanocomposite: the magnesium matrix appears in light grey and the boundaries between former powder particles in dark grey. The arrows denote elongated pores which appear in black.
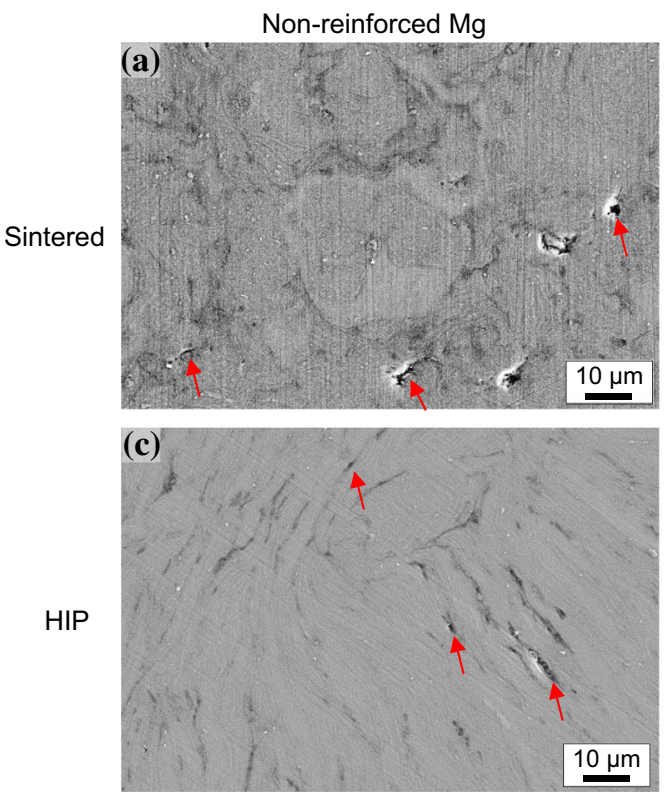
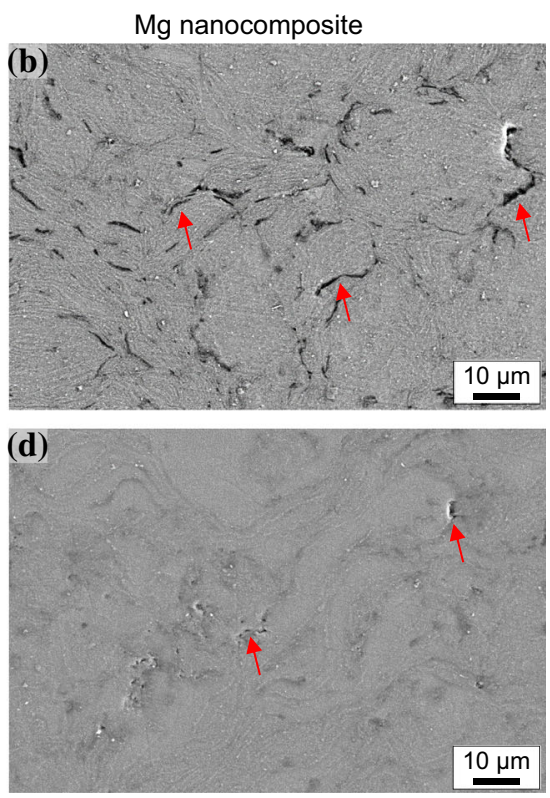

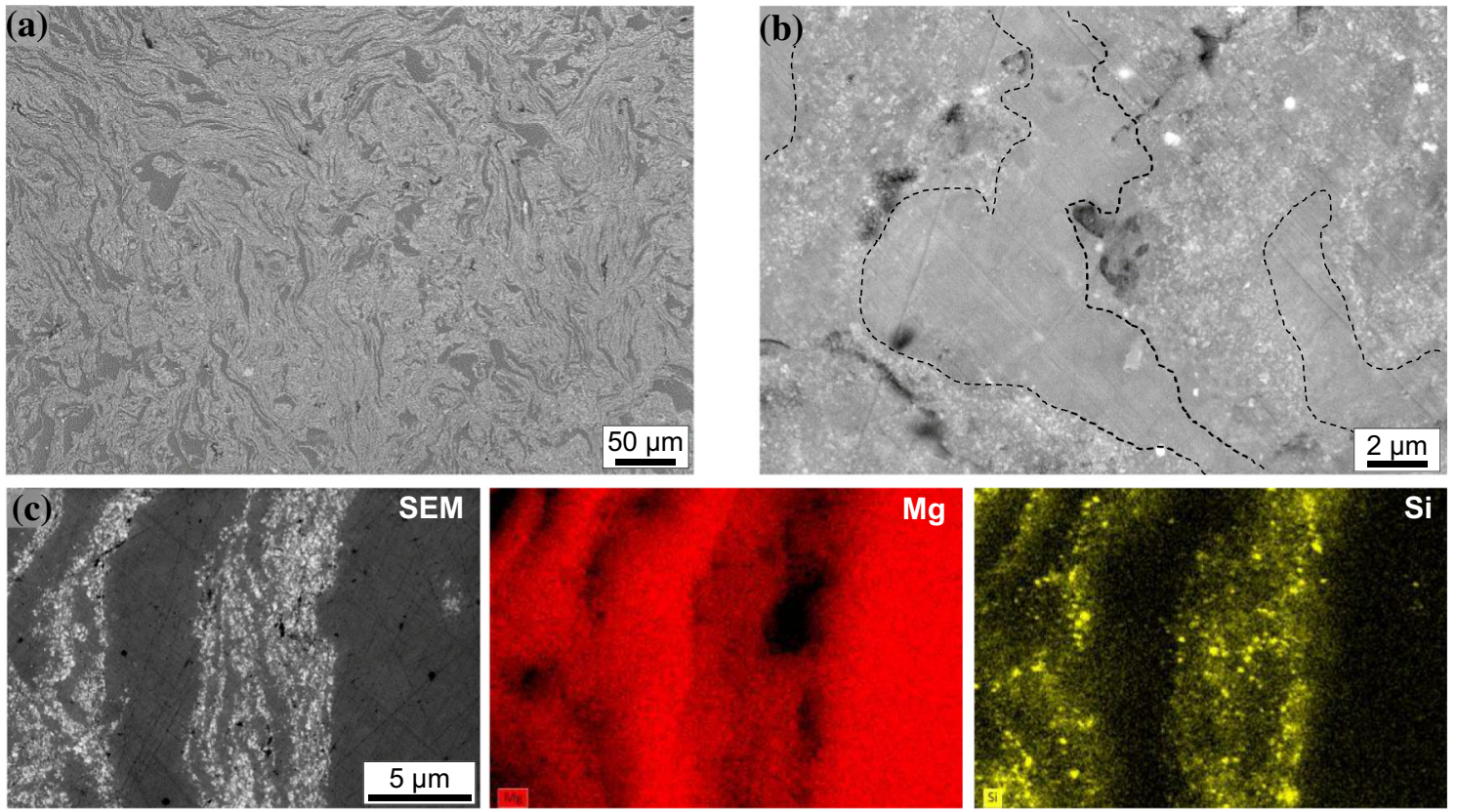

Figure 2 SEM micrographs of a cross section of a HIPed $\mathrm{Mg}$ nanocomposite specimen: a enhanced material contrast imaging reveals differences in, the microstructure where some areas appear in darker grey and others in light grey; $\mathbf{b}$ detailed view at higher magnification (areas that appear in dark grey at lower

To further analyse the microstructure of the two different regions of the HIPed $\mathrm{Mg}-\mathrm{SiC}$ in terms of grain size and $\mathrm{SiC}$ distribution, TEM analyses were performed. The two regions can be clearly distinguished in the dark-field TEM micrograph in Fig. 3a. At the top and the bottom of this figure, the SiC-free regions are visible, while the $\mathrm{SiC}$-containing region is located in between. Figure $3 b$ shows the SiC-free region in higher magnification illustrating large $\mathrm{Mg}$ grains, which are surrounded by white particles. These are $\mathrm{MgO}_{\mathrm{x}}$, located at the grain boundaries of the $\mathrm{Mg}$ matrix in the SiC-free regions, as shown by EDX (Fig. 3c). The EDX analysis also affirms that no $\mathrm{SiC}$ nanoparticles exist within the $\mathrm{Mg}$ grains. The bright-field TEM micrograph in Fig. $3 d$ shows that the $\mathrm{SiC}$-containing region has small equiaxed $\mathrm{Mg}$ grains, with a homogeneous distribution of $\mathrm{SiC}$ nanoparticles throughout the grains. The grain size distribution was evaluated separately in the different areas and is displayed together in Fig. 3e. The grain size distribution is bimodal. The large amount of small grains belongs to the $\mathrm{SiC}$-containing region, and the smaller number of larger grains with sizes greater than $1 \mu \mathrm{m}$ belongs to the SiC-free region. magnification are surrounded by dashed lines): these areas appear smoother and more homogeneous, while the areas that appear brighter at lower magnification look more heterogenous; c micrograph and corresponding elemental maps of magnesium and silicon showing that Si only appears in the light grey areas.

Averaging over both regions, we determined a grain size of $270 \mathrm{~nm}$.

\section{Mechanical properties}

The average Vickers microhardness of all four material compositions and states is shown in Fig. 4. Considering the determined grain sizes, the Vickers indent, exhibiting a size of 40-50 $\mu \mathrm{m}$, includes a high number of grains, thus leading to an average hardness value. On the microscale, for both materials a slight increase in hardness is observed after HIP compared to the sintered state. The HIPed Mg-SiC has the highest Vickers hardness with an increase to 49.3 HV 0.2. All states except the sintered Mg-SiC and the HIPed $\mathrm{Mg}$ differ statistically significantly.

The mechanical properties on the nanoscale, and, specifically, the local property variations due to the two different, SiC-free and SiC-containing regions, in the HIPed nanocomposite were assessed by nanoindentation. Typical load-displacement curves are shown in Fig. 5. The shape of the curves is typical for an elastic-plastic behaviour. For the sintered states, the load-displacement curves are smooth, while both HIPed samples show small pop-in effects. The curves 

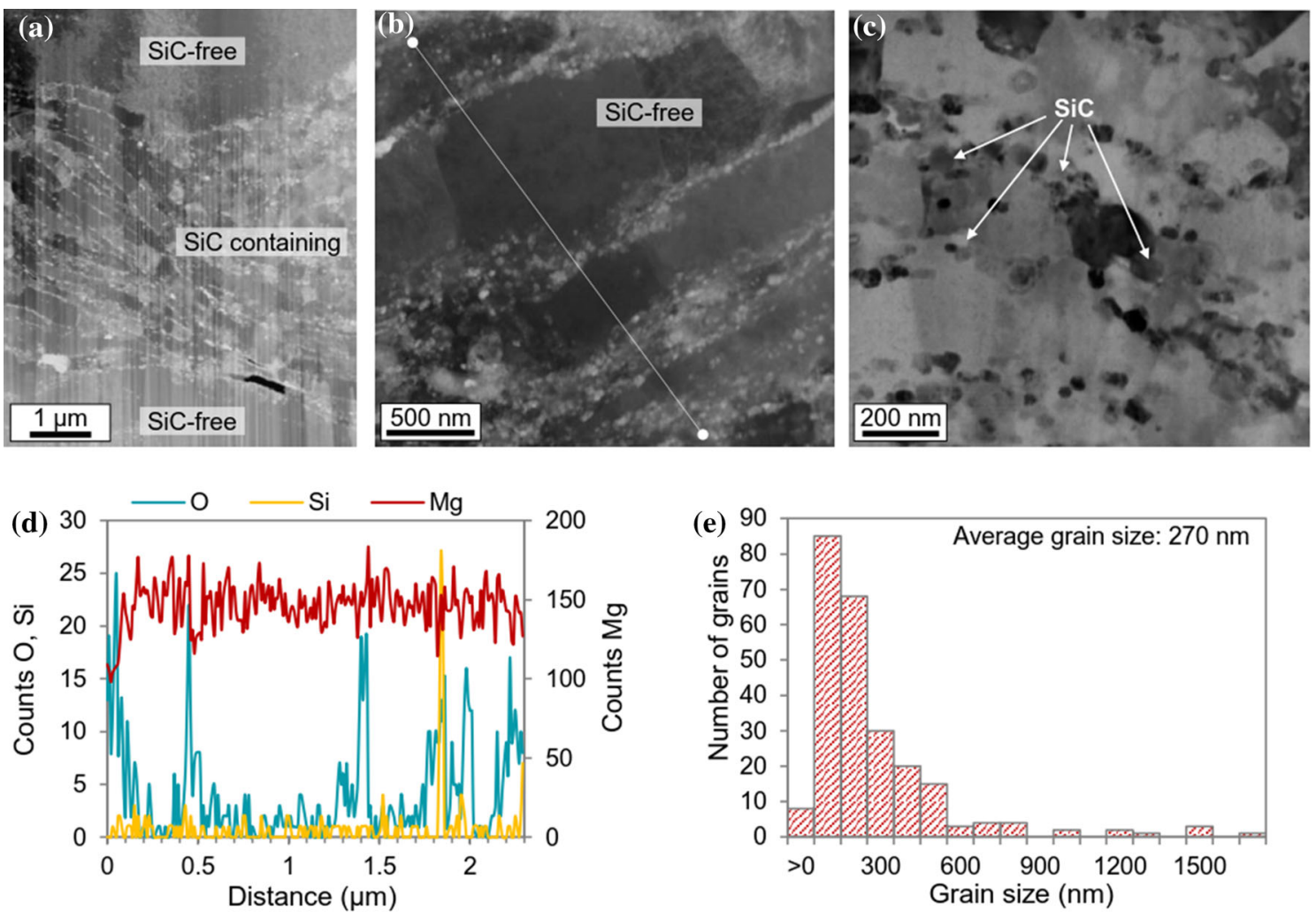

Figure 3 TEM micrographs of a HIPed $\mathrm{Mg}$ nanocomposite specimen: a dark-field (DF) micrograph showing the overall microstructure parallel to the uniaxial pressing direction: $\mathrm{SiC}$-free regions (top and bottom, appear light grey in SEM) and SiCcontaining region in between (appears dark grey in SEM), vertical lines are artefacts from sample preparation; $\mathbf{b}$ DF image showing

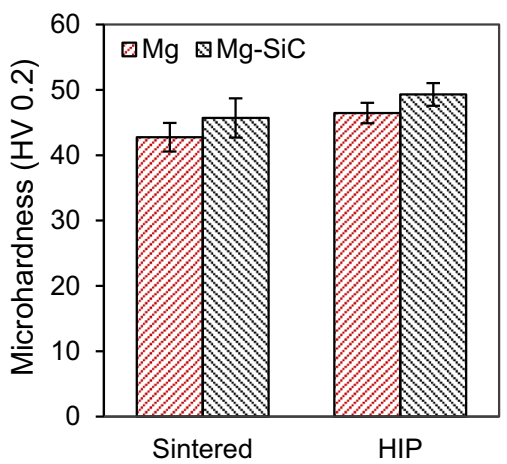

Figure 4 Average Vickers microhardness values (HV 0.2): the differences between all states are significantly different with the exemption of the difference between the sintered $\mathrm{Mg}$ nanocomposite and the HIPed non-reinforced $\mathrm{Mg}$. The black vertical lines denote the standard deviation.

of the $\mathrm{Mg}$ nanocomposite are shifted slightly towards lower displacements ("to the left") compared to the non-reinforced $\mathrm{Mg}$, reflecting a higher resistance to

the $\mathrm{SiC}$-free region, line scan in $\mathrm{d}$ is denoted by the white line; c bright-field micrograph showing $\mathrm{SiC}$ nanoparticles in the $\mathrm{SiC}$ containing region which are marked with arrows; $\mathbf{d}$ line scan along the direction; e statistical grain size distribution shows large amount of small grains belonging to the SiC-containing regions and a low amount of large grains belonging to the SiC-free region.

deformation. The nanoindents of the sintered and HIPed samples (Fig. 5) have a size of approximately 1 to $2 \mu \mathrm{m}$ and show no signs of crack initiation. Brighter areas, visible at the edges of the imprints, suggest minor pile-up.

Figure 6 summarises the nanoindentation results. Compared to the sintered samples, only the nanohardness of $\mathrm{Mg}$ increased significantly through HIP. The HIPed Mg and the HIPed Mg-SiC show the highest average nanohardness values, with 0.83 and $0.86 \mathrm{GPa}$, respectively, but these values are not statistically significantly different from each other.

The average $E_{\text {eff }}$ of the HIPed materials, both in the non-reinforced $\mathrm{Mg}$ and in the reinforced state, statistically significantly decreased by 7.5 and $9.7 \%$, respectively, compared to the sintered samples. However, in all cases, the addition of the hard SiC nanoparticles increased the effective elastic modulus of the $\mathrm{Mg}$ nanocomposite as compared to the nonreinforced state. 

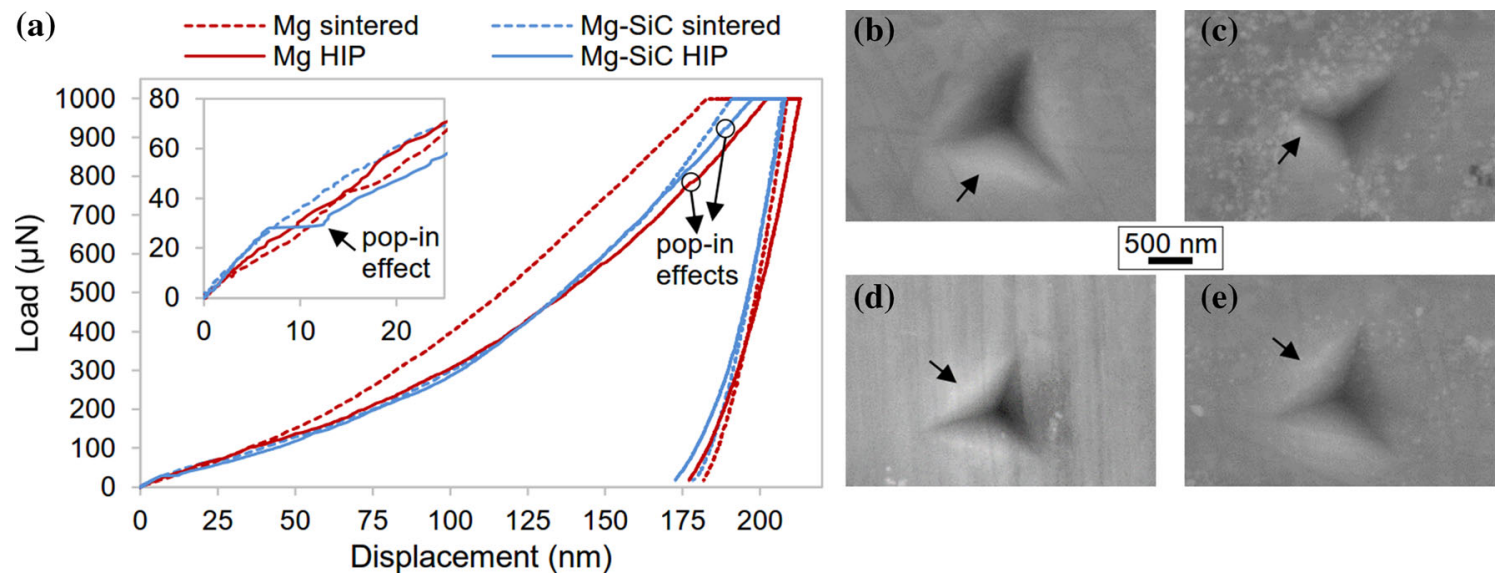

Figure 5 a Load-displacement curves obtained by nanoindentation with a maximum load of $1 \mathrm{mN}$. Only the HIPed samples show a pop-in effect for low loads (inset). b-e SEM images of typical indents on $\mathbf{b}, \mathbf{c}$ sintered and $\mathbf{d}, \mathbf{e}$ HIPed cross

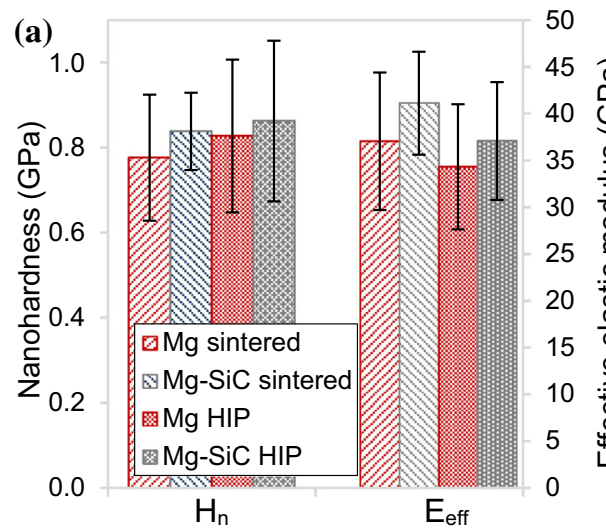

Figure 6 a Average nanohardness and effective elastic modulus $\left(\mathrm{E}_{\text {eff }}\right)$ values of non-reinforced $\mathrm{Mg}$ and $\mathrm{Mg}$ nanocomposite in the sintered and HIPed states; $\mathbf{b}$ Influence of the local microstructure on the nanohardnesses and the $E_{\text {eff }}$ of $\mathrm{Mg}$ nanocomposite: SiC-free

The local nanohardness and effective elastic modulus values of the $\mathrm{SiC}$-free and the $\mathrm{SiC}$-containing regions in the HIPed $\mathrm{Mg}-\mathrm{SiC}$ are shown in Fig. $6 \mathrm{~b}$. While $\mathrm{E}_{\text {eff }}$ shows no difference, the nanohardness of the $\mathrm{SiC}$-free regions $(0.74 \mathrm{GPa})$ is lower than nanohardness of the SiC-containing regions (0.91 GPa).

\section{Discussion}

Hot isostatic pressing has been routinely used for the production of standard sintered materials to achieve isotropic densification of metal and ceramic powders sections of non-reinforced $\mathrm{Mg}$ (left: $\mathbf{b}, \mathbf{d}$ ) and $\mathrm{Mg}$ nanocomposite (right: c, e): minor pile-up is observed at the indent edges, visible as rims in lighter grey at the edges of the triangular indents, marked with arrows.

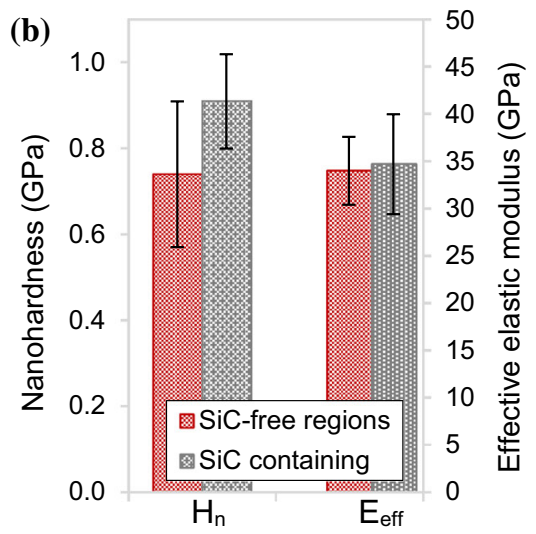

regions possess significantly lower nanohardness than the SiCcontaining regions, while $E_{\text {eff }}$ is comparable. The vertical black lines denote the standard deviation.

before sintering. Here, we investigated an alternative use of HIP as an additional processing step to densify $\mathrm{Mg}-\mathrm{SiC}$ nanocomposites following pressing and sintering of nanostructured composite powders. We compared the outcome with hot extrusion, another uniaxial hot forming process. Due to the combined application of high pressure and high temperature, HIP is expected to profoundly modify the microstructure of the nanocomposites. Indeed, we observed significant changes in the size and shape of the pores, the grain size and the distribution of the nanoparticles. Furthermore, and importantly, the density increased. All in all, however, the mechanical properties stayed below the expected values: the high 
temperature allowed significant grain growth, leading to a coarsening of the microstructure and to the formation of $\mathrm{SiC}$-free regions. These negative effects were not sufficiently counteracted by the positive effect of the higher density. We therefore conclude that either the isostatically applied pressure was not high enough to induce sufficient plastic deformation, or the temperature was too high, so that the coarsening of the microstructure happened too fast. Dynamic recrystallisation therefore either was totally hindered by the effect of Zener pinning by the nanoparticles, or it did not take place to an extent sufficient to counterbalance the coarsening.

In principle, at the pressure and temperature applied, a variety of deformation mechanisms are possible during HIP. Due to the ultrafine microstructure of our $\mathrm{Mg}$ nanocomposite, grain boundary sliding (GBS) and Coble creep may be expected to take place. Based on the densification map of Frost and Ashby for pure Mg [16], we may safely assume that dislocation creep and volume diffusion are the most likely mechanisms, besides Coble creep. In contrast, Dieringa expects that, at temperatures between 200 and $300{ }^{\circ} \mathrm{C}$, dislocation creep and grain boundary sliding are the mechanisms preferred to Coble creep and volume diffusion [17]. Dynamic recrystallisation and Nabarro-Herring creep, on the other hand, are less likely because these mechanisms are known to occur only at higher temperatures than those we used. Furthermore, SiC nanoparticles and other fine oxide particles are well known to extensively increase the creep resistance by pinning dislocations and hindering grain boundary diffusion [18, 19].

Based on our findings, we propose the model shown in Fig. 7 that schematically describes which deformation mechanisms we assume to be active, and the sequence of events during the microstructure evolution of our materials. Ideally, the SiC nanoparticles should be homogeneously distributed in the $\mathrm{Mg}-\mathrm{SiC}$ nanocomposites. The real microstructure, however, is inhomogeneous with some $\mathrm{Mg}$ grains lacking $\mathrm{SiC}$ nanoparticles along their grain boundaries. Thus, some grain boundaries are not pinned. Consequently, due to the relatively long exposure time to elevated temperatures during the HIP process, and due to the high thermodynamic pressure because of the very fine grains, grain growth is likely to occur in these areas. Concomitantly, in areas with less nanoparticles, these move together with the grain boundaries [20] and a region devoid of $\mathrm{SiC}$ nanoparticles and with a coarser grain size develops. Eventually, the migrating grain boundaries meet more and more nanoparticles until they are stopped. In areas where $\mathrm{SiC}$ nanoparticles are homogeneously distributed, grain growth is hindered through Zener pinning, and so are grain boundary sliding, dynamic recrystallisation, Coble creep and the overall diffusion. Additionally, we assume that $\mathrm{MgO}$ can act as a barrier and suppress volume diffusion to the grain interior. This corroborates the findings of Dadbakhsh and Hao in $\mathrm{Al}-\mathrm{Fe}_{2} \mathrm{O}_{3}$ composites [21]. The existence of large $\mathrm{Mg}$ grains in a former ultrafine microstructure was also reported by Yao et al. for an Al6063-SiC nanocomposite after extrusion [20]. The authors explained this finding with the higher internal driving force for grain growth compared to the dragging force of few individual nanoparticles, that is, Zener pinning. In pure $\mathrm{Mg}$, the fine $\mathrm{MgO}$ particles prevent the grain growth; however, the dragging force is not as great as that of the larger nanoparticles, which is why the grains can grow larger.

Interestingly, the $\mathrm{Mg}$ nanocomposite showed a higher densification during HIP than the non-reinforced $\mathrm{Mg}$. This may be explained by the finer grain size and, thus, the higher number of grain boundaries present in the $\mathrm{Mg}$ nanocomposite which allows more grain boundary diffusion and sliding, despite the nanoparticles. TEM investigations could help clarify the mechanisms. However, visualising dislocations in the hcp crystal structure is very complex and challenging, especially if the grain orientations of the nano-sized $\mathrm{Mg}$ grains in the TEM foil are not known. In principle, EBSD analysis is a possibility to characterise the grain orientations in a TEM foil; however, this is not feasible in the $\mathrm{Mg}$ nanocomposites due to their extremely small grain size.

Densification of the $\mathrm{Mg}$ nanocomposites during HIP was lower than what we observed during hot extrusion [11]. Possible reasons are the very low strain rates and the uniform pressure during HIP. The latter leads to a uniform stress distribution within the specimen, and shear stresses are negligible. As a consequence, the overall amount of plastic deformation is lower and, thus, pore removal is less effective because the driving force for dynamic recrystallisation is lower. Additionally, due to the longer process time of HIP ( $>1 \mathrm{~h}$ compared to a few minutes for hot extrusion), there is more time for diffusion. We may safely assume that the longer time 


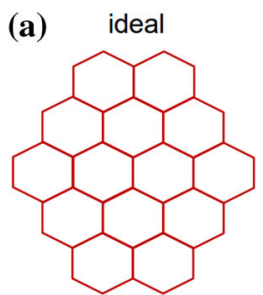

(b)
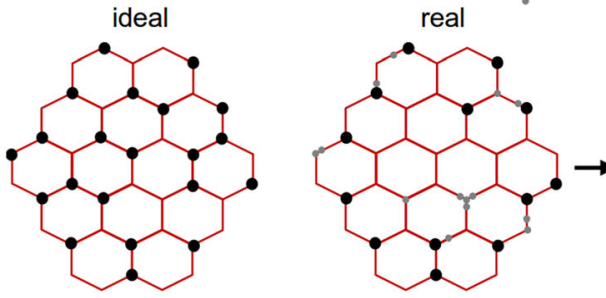

Figure 7 Schematic illustrations of ideal and real microstructures including a model of the possible mechanisms involved for a pure $\mathrm{Mg}$ and $\mathbf{b} \mathrm{Mg}-\mathrm{SiC}$ nanocomposite. $\mathrm{Mg}$ grains keep their shape due to the applied isostatic pressure. The internal driving force for grain growth is higher than the dragging force of the few

supports some diffusion driven processes, which assist in increasing the density, and lead to a rounding of the formerly elongated pores of the $\mathrm{Mg}$ nanocomposite during HIP. However, the increase in density is small and other mechanisms seem more likely to contribute to densification than diffusion driven processes, as discussed above.

The microstructural features, such as grain size and $\mathrm{SiC}$ distribution, strongly influence the mechanical properties, according to the Hall-Petch relationship and the Orowan mechanism, respectively. The development of few SiC-free regions with their relatively large $\mathrm{Mg}$ grains appears to be sufficient to reduce the microhardness, so that no significant improvement can be observed compared to the sintered state despite the increase in density. Nanoindentation showed that the SiC-free regions indeed exhibit a lower local nanohardness; this may be due to deformation twinning, which is an additional deformation mechanism besides sliding of dislocations and which has been observed to take place in coarse-grained $\mathrm{Mg}$ to a greater extent [22]. The pop-in observed in the loading curve of the nanoindentation loading cycle corroborates twinning, as also described by $\mathrm{Hu}$ et al. [23]. Thus, in addition to the lower effective elastic modulus, the $\mathrm{SiC}$-free regions are expected to allow a higher amount of plastic deformation. Note that the increase in $E_{\text {eff }}$ in the $\mathrm{Mg}$ nanocomposite compared to $\mathrm{Mg}$ is mainly due to the individual $\mathrm{SiC}$ nanoparticles or $\mathrm{MgO}$ particles. When a certain amount of particles has accumulated, the grain boundary movement is stopped by Zener pinning, which also hinders recrystallisation.

higher elastic modulus of the $\mathrm{SiC}$ nanoparticles. The indents have edge lengths in the range of 1 to $2 \mu \mathrm{m}$ and depths in the range of $200 \mathrm{~nm}$. They are therefore much larger than the nanoparticles which exhibit sizes of up to $50 \mathrm{~nm}$ at maximum. We may therefore safely assume that nearly always both phases, the $\mathrm{Mg}$ matrix and the $\mathrm{SiC}$ nanoparticles are present in the indented volume, however, with locally varying relative contents. This explains the high scatter of the results, and the higher $E_{\text {eff }}$ of the nanocomposites as compared to the pure Mg. Furthermore, high standard deviations of $E_{\text {eff }}$ and of the nanohardness are expected, because there may be grain boundaries below the surface in the region of the indented volume which will surely influence the plastic deformation and thus the nanoindentation results.

After HIP, the result is a material with pronounced stress and strain inhomogeneity during mechanical loading. On the one hand, this heterogeneity may be disadvantageous; on the other hand, the more ductile SiC-free regions might also be beneficial in slowing cracks down. Further tests on macroscopic specimens are needed to evaluate the full potential of the nanocomposites after different processing steps. 


\section{Conclusions}

Here, we report on the effect of hot isostatic pressing on the densification, the microstructure evolution and the mechanical properties measured by micro- and nanoindentation of a $\mathrm{Mg}-\mathrm{SiC}$ nanocomposite. As compared to uniaxial hot forming processes, HIP is a promising alternative because the isostatic pressure may help preventing the development of a texture as it usually develops in the hcp $\mathrm{Mg}$ materials during hot extrusion, for instance. Even though we achieved an increase in density no increase in the mechanical properties was achieved, mainly due to grain growth and the development of SiC-free, non-reinforced regions. Since the isostatic pressure causes too little shear and, therefore, deformation energy is low, dynamic recrystallisation is not induced and the increase in density is limited. Technologically, pressures up to $200 \mathrm{MPa}$ are possible. However, based on our observations and the discussion of possible deformation mechanisms, we may safely assume that doubling the pressure will not have a major influence on the densification. This is mainly due to the hindering of deformation mechanisms by nanoparticles. Further studies need to be carried out in order to validate the assumed mechanisms.

\section{Acknowledgement}

Open Access funding provided by Projekt DEAL. The authors gratefully acknowledge the financial support by the DFG (Deutsche Forschungsgemeinschaft). We also acknowledge Claudia Fasel from the group Dispersive Solids, Institute of Materials and Earth Sciences at TU Darmstadt, for her support during material production and the Non-Metallic Inorganic Materials group for providing technical cooperation. We further thank Jan Räthel from the Fraunhofer Institute for Ceramic Technologies and Systems (IKTS, Dresden) for performing the sinter and HIP process. The SEM and TEM analyses were performed at the Central Electron Microscopy Unit (ZELMI) of TU Berlin. The authors thank Christoph Fahrenson and Sören Selve for their valuable support during these measurements.

\section{Compliance with ethical standards}

Conflicts of interest The authors declare that they have no conflict of interest.
Open Access This article is licensed under a Creative Commons Attribution 4.0 International License, which permits use, sharing, adaptation, distribution and reproduction in any medium or format, as long as you give appropriate credit to the original author(s) and the source, provide a link to the Creative Commons licence, and indicate if changes were made. The images or other third party material in this article are included in the article's Creative Commons licence, unless indicated otherwise in a credit line to the material. If material is not included in the article's Creative Commons licence and your intended use is not permitted by statutory regulation or exceeds the permitted use, you will need to obtain permission directly from the copyright holder. To view a copy of this licence, visit http://creativecommons.org/licen ses/by $/ 4.0 /$.

\section{References}

[1] Ibrahim IA, Mohamed FA, Lavernia EJ (1991) Particulate reinforced metal matrix composites - a review. J. Mat. Sci. 26:1137-1156. https://doi.org/10.1007/BF00544448

[2] Tjong SC (2007) Novel nanoparticle-reinforced metal matrix composites with enhanced mechanical properties. Adv Eng Mater 9(8):639-652

[3] Shen MJ, Ying WF, Wang XJ, Zhang MF, Wu K (2015) Development of high performance magnesium matrix nanocomposites using nano-SiC particulates as reinforcement. J Mater Eng Perform 24(10):3798-3807

[4] Bocanegra-Bernal MH (2004) Hot isostatic pressing (HIP) technology and its applications to metals and ceramics. J Mater Sci 39:6399-6420. https://doi.org/10.1023/B:JMSC. 0000044878.11441.90

[5] Atkinson HV, Davies S (2000) Fundamental aspects of hot isostatic pressing: an overview. Metall Mat Trans A 31(12):2981-3000

[6] Viswanathan V, Laha T, Balani K, Agarwal A, Seal S (2006) Challenges and advances in nanocomposite processing techniques. Mater Sci Eng R Rep 54(5-6):121-285

[7] Loh NL, Sia KY (1992) An overview of hot isostatic pressing. J Mater Process Technol 30(1):45-65

[8] Swinkels FB, Wilkinson DS, Arzt E, Ashby MF (1983) Mechanisms of hot-isostatic pressing. Acta Mater 31(11):1829-1840

[9] Lange FF, Atteraas L, Zok F, Porter JR (1991) Deformation consolidation of metal powders containing steel inclusions. Acta Mater 39(2):209-219 
[10] Xu ZM, Loh NL, Zhou W (1997) Hot isostatic pressing of cast $\mathrm{SiC}_{\mathrm{p}}$-reinforced aluminium-based composites. In: 7 th international scientific conference: achievements in mechanical \& materials engineering 67(1):131-136

[11] Penther D, Ghasemi A, Riedel R, Fleck C, Kamrani S (2018) Effect of $\mathrm{SiC}$ nanoparticles on manufacturing process, microstructure and hardness of $\mathrm{Mg}-\mathrm{SiC}$ nanocomposites produced by mechanical milling and hot extrusion. Mater Sci Eng A 738:264-272

[12] Kamrani S, Penther D, Ghasemi A, Riedel R, Fleck C (2018) Microstructural characterization of $\mathrm{Mg}-\mathrm{SiC}$ nanocomposite synthesized by high energy ball milling. Adv Powder Technol 29:1742-1748

[13] Oliver WC, Pharr GM (1992) An improved technique for determining hardness and elastic modulus using load and displacement sensing indentation experiments. J Mater Res 7(06): 1564-1583

[14] Oliver WC, Pharr GM (2004) Measurement of hardness and elastic modulus by instrumented indentation: advances in understanding and refinements to methodology. J Mater Res 19(01):3-20

[15] Kim TK (2015) T test as a parametric statistic. Korean J. Anesthesiol. 68(6):540-546

[16] Frost HJ, Ashby MF (1982) Deformation-mechanism maps the plasticity and creep of metals and ceramics, 1 st edn. Pergamon Press, Oxford

[17] Dieringa H (2011) Properties of magnesium alloys reinforced with nanoparticles and carbon nanotubes: a review. J Mat Sci 46:289-306. https://doi.org/10.1007/s10853-0105010-6
[18] Basak AK, Pramanik A, Islam MN, Anandakrishnan V (2015) In: Lau AKT, Umer R, Dong Y (eds) Fillers and reinforcements for advanced nanocomposites. Woodhead Publishing is an imprint of Elsevier, Cambridge, pp 349-367

[19] Park K-T, Lavernia EJ, Mohamed FA (1990) High temperature creep of silicon carbide particulate reinforced aluminum. Acta Mater 38(11):2149-2159

[20] Yao X, Zheng YF, Quadir MZ, Kong C, Liang JM, Chen YH, Munroe P, Zhang DL (2018) Grain growth and recrystallization behaviors of an ultrafine grained Al$0.6 \mathrm{wt} \% \mathrm{Mg}-0.4 \mathrm{wt} \% \mathrm{Si}-5 \mathrm{vol} . \% \mathrm{SiC}$ nanocomposite during heat treatment and extrusion. J. Alloys Compd 745:519-524

[21] Dadbakhsh S, Hao L (2012) Effect of hot isostatic pressing (HIP) on $\mathrm{Al}$ composite parts made from laser consolidated $\mathrm{Al} / \mathrm{Fe}_{2} \mathrm{O}_{3}$ powder mixture. In: 7th International scientific conference: achievements in mechanical \& materials engineering 212(11):2474-2483

[22] Bočan J, Maňák J (2005) Jäger A (2015) Nanomechanical analysis of AZ31 magnesium alloy and pure magnesium correlated with crystallographic orientation. Int Symp Phys Mater 644:121-128

[23] Hu J, Zhang W, Bi G, Lu J, Huo W, Zhang Y (2017) Nanoindentation creep behavior of coarse-grained and ultrafine-grained pure magnesium and AZ31 alloy. Mater Sci Eng A 698:348-355

Publisher's Note Springer Nature remains neutral with regard to jurisdictional claims in published maps and institutional affiliations. 